\title{
ESTRATÉGIAS DE LEITURA E MEDIAÇÃO DO PROFESSOR: O DESAFIO DE FORMAR LEITORES NO TERCEIRO DO ENSINO FUNDAMENTAL
}

\author{
ESTRATEGAIS DE LECTURA Y MEDIACIÓN DEL PROFESOR: EL \\ DESAFÍO DE FORMAR LECTORES EN EL TERCER AÑO DE LA ENSEÑANZA \\ FUNDAMENTAL
}

\begin{abstract}
STRATEGIES READING AND TEACHER'S MEDIATION: THE FORM OF CHALLENGE READERS IN THIRD YEAR OF ELEMENTARY SCHOOL
\end{abstract}

\author{
Maria Aparecida Lopes ROSSI ${ }^{1}$ \\ Selma Martines PERES ${ }^{2}$ \\ Fernanda Siqueira da SILVA ${ }^{3}$
}

\begin{abstract}
RESUMO: O presente artigo problematiza dados de pesquisa realizada em uma cidade do interior do sudeste goiano com o objetivo de perceber como tem se desenvolvido o trabalho com a leitura no $3^{\circ}$ ano do Ensino Fundamental I e quais estratégias de leitura são utilizadas no trabalho desenvolvido na sala de aula. A pesquisa foi realizada a partir de uma abordagem qualitativa de caráter etnográfico. Como instrumento de coleta de dados foi realizada uma entrevista semiestruturada e observadas cinco aulas. No âmbito da presente discussão, problematizamos os dados coletados durante as observações. $\mathrm{O}$ arcabouço teórico-conceitual das estratégias de leitura é expresso a partir dos estudos de Masetto, Solé, Moura e Martins, Girotto e Souza, Antunes entre outros. Tais estudos destacam o papel do professor na formação de leitores, o qual deve propor estratégias, procedimentos e atividades que facilitem e proporcionem a compreensão em leitura dos alunos. Ao final das análises, o que destacamos é que de cinco aulas voltadas para o ensino de leitura, em duas delas o objetivo principal foi levar os alunos à memorização da ortografia e conteúdo gramatical. As estratégias de leitura mais utilizadas foram a predição e a inferência.
\end{abstract}

PALAVRAS-CHAVE: Estratégias de leitura. Mediação pedagógica. Formação do leitor.

RESUMEN: El presente artículo problematiza datos de investigación realizada en una ciudad del interior del sudeste del estado de Goiás (Brasil) con el objetivo de percibir como se ha desarrollado el trabajo con la lectura en el tercer año de la Enseñanza Fundamental I y cuales estrategias de lectura son utilizadas en el trabajo desarrollado en sala de clase. La investigación fue realizada a partir de un abordaje cualitativo de carácter etnográfico. Como instrumento de recopilación de datos fue realizada una entrevista semiestructurada y observadas cinco clases. En el ámbito de la presente discusión, problematizamos los datos recopilados a lo largo de las observaciones. El aporte teórico-conceptual de las estrategias de lectura se expresa a partir de los estudios de Masetto, Solé, Moura y Martins, Giroto y Souza, Antunes entre otros.

\footnotetext{
${ }^{1}$ Doutora em Educação. Professora da Unidade Acadêmica Especial de Educação - PPGEDUC/UFG. Programa de Pós Graduação em Educação, Catalão, Brasil. E-mail: picidarossi@ gmail.com.

${ }^{2}$ Doutora em Educação. Professora da Unidade Acadêmica Especial de Educação - PPGEDUC/UFG. Programa de Pós Graduação em Educação, Catalão, Brasil. E-mail: selmamartines@uol.com.br.

${ }^{3}$ Mestre em Educação - PPGEDUC/UFG. Programa de Pós Graduação em Educação, Catalão, Brasil. Email: fernanda2504@outlook.com.
} 
Dichos estudios destacan el papel del profesor en la formación de lectores, el cual debe proponer estrategias, procedimientos y actividades que faciliten y proporcionen la comprensión en lectura de los alumnos. Al final de los análisis, lo que destacamos es que de cinco clases dirigidas para la enseñanza de lectura, en dos de ellas el objetivo principal fue llevar los alumnos a la memorización de la ortografía y contenido gramatical. Las estrategias de lectura más utilizadas fueron la predicción y la inferencia.

PALABRAS CLAVE: Estrategias de lectura. Mediación pedagógica. Formación del lector.

ABSTRACT: This article discusses research data held in a city in southeast of Goiás, in order to see how it has developed the work with reading the third year of elementary school and which reading strategies are used in the work in the classrooms. The survey was conducted from a qualitative approach of ethnographic character. Was held a semi-structured interview and observed five classes as data collection instrument. In the context of this discussion, we render problematic the data collected during the observations. The theoretical and conceptual framework of reading strategies is expressed from Masetto studies, Solé, and Moura Martins, Girotto and Souza Antunes among others. These studies highlight the teacher's role in the formation of readers, which must propose strategies, procedures and activities that facilitate and provide the reading comprehension of students. At the end of the analysis, we can highlight five lessons aimed at teaching reading, in two of them the main aim was to bring students to memorize the spelling and grammatical content. The most used reading strategies were predicting held and inference.

KEYWORDS: Reading strategies. Pedagogical mediation. Reader formation.

\section{Introdução}

A educação deve ter como uma das preocupações centrais a formação do indivíduo crítico, atuante e participante na sociedade. Neste sentido, a leitura ocupa um papel fundamental nessa formação, uma vez que propicia ao indivíduo a capacidade de desenvolver sua autonomia, ampliar o conhecimento e despertar o imaginário. Assim, contribui para que os sujeitos tenham uma visão crítica da sociedade, percebendo que lugar e papel nela devem desempenhar. Como ressaltam Moura e Martins (2012, p.87):

A leitura é essencial para o indivíduo construir seu próprio conhecimento e exercer seu papel social no contexto da cidadania, pois a capacidade leitora amplia o entendimento de mundo, propicia o acesso à informação, facilita a autonomia, estimula a fantasia e a imaginação e permite a reflexão crítica, o debate e a troca de ideias.

Ancorados nessa concepção, os Parâmetros Curriculares Nacionais (PCN), no que se refere ao ensino de língua portuguesa, apontam que a leitura é o "[...] processo no 
qual o leitor realiza um trabalho ativo de compreensão e interpretação do texto a partir de seus objetivos, de seu conhecimento sobre o assunto, sobre o autor, de tudo o que sabe sobre a linguagem, etc.”. (BRASIL, 1997, p.69).

Assim, espera-se do leitor que este consiga ser competente, tendo a capacidade de, através dos seus conhecimentos prévios, estabelecer uma relação entre o texto e o mundo. Um leitor competente não é apenas aquele que decifra uma mensagem, mas sim aquele que constrói sentidos para o texto que está lendo, questionando e realizando inferências a partir de seu conhecimento de mundo. Nesse sentido, a leitura é compreendida como uma atividade que vai além da simples relação fonemas/grafemas. Ler implica compreender, percebendo-se a compreensão como um processo de construção de significados sobre o texto lido.

Sobre o processo de compreensão na atividade de leitura, Fischer (2006, p.302) afirma que:

[...] fazemos o processamento de informação de modo pessoal, visualizamos, sentimos emoções, fazemos inferências e referencias cruzadas e realizamos muitas outras complexas atividades cerebrais, quase ao mesmo tempo. A leitura ocorre independentemente dos grafemas individuais pretos em uma página branca ou na tela do computador, os quais são registrados apenas em um nível inferior e quase inconsciente de percepção e processamento. Alguns estudiosos acreditam que a leitura seja uma atividade tão complexa quanto pensar.

Desde modo, a leitura deve envolver o processo de compreensão pautado no letramento ativo, no qual o leitor se forma leitor ao interagir com o texto lido, por meio da ação do professor ou de mediadores de leitura. Ler torna-se, assim, uma forma para aprender significativamente. Quando o aluno compreende o que leu está aprendendo.

Por isso, a importância de despertar nos alunos a vontade de ler, e o professor, enquanto mediador, deve auxiliá-los nesse processo. Cabe ao professor levar os alunos a utilizarem estratégias de compreensão estimulando-os a fazer conexões com as suas experiências, conhecimento de mundo e o texto.

Segundo Girotto e Souza (2010, p.54), “[...] a criança forma-se como leitora, ao construir seu saber sobre texto e leitura, conforme as atividades que lhe são propostas pelo mediador durante o processo de planejar, organizar, e implementar atividades de leitura literária".

A leitura se configura como uma experiência cultural, capaz de transformar e modificar a mente histórico-cultural dos sujeitos, se constituindo como uma atividade 
complexa, na qual o leitor se relaciona com outros e com o mundo. Para Bajard (2002, p.42) “[...] a leitura é o produto de uma interação entre o leitor e o texto, e não uma decodificação de um significante, desvelamento de um sentido pré-existente; convocando seus referenciais culturais, o leitor constrói o sentido do texto".

Nessa mesma direção, Orlandi (1998), salienta que a leitura é uma questão linguística, pedagógica e social, sendo papel da escola e do professor propiciar condições necessárias para que os alunos tornem-se leitores autônomos, promovendo a capacidade deles de pensar e julgar o que estão lendo.

Um dos mecanismos que podemos utilizar para que a escola consiga cumprir com o seu papel de formadora de indivíduos autônomos, é utilizar as estratégias de leitura no trabalho desenvolvido na sala de aula em que o professor torna-se um mediador desse processo de propiciar as relações entre leitor/texto/autor assim como tratam os autores Masetto (2000), Solé (1998), Moura e Martins (2012), Girotto e Souza (2010), entre outros.

Segundo Solé (1988), as estratégias de leitura estão presentes no processo de leitura e são as ferramentas necessárias para o desenvolvimento da leitura proficiente. Sua utilização permite aos alunos compreender e interpretar, de forma autônoma, os textos lidos.

Girotto e Souza (2010) lembram que discutir o uso de estratégias no ensino de leitura implica em discutir também sobre o letramento ativo, pois quando o ensino se dá no âmbito do letramento ativo, este é mais efetivo. Vez que "[...] o ensino de leitura baseado no 'letramento ativo' pressupõe a tomada de consciência de estratégias de leitura desde a educação infantil”. (GIROTTO; SOUZA, 2010, p.48).

Destacando no processo de ensino/aprendizagem, o papel dos textos literários, as autoras ressaltam que:

O objetivo de aula, de professores de leitura literária, deve ser, explicitamente, ensinar um repertório de estratégias para aumentar o motivo do entendimento e interesse pela leitura. Ou seja, deve-se ofertar situações para que as crianças possam monitorar e ampliar o entendimento, bem como adquirir e ativar o seu conhecimento de mundo, linguístico e textual, a partir do que estão lendo. (GIROTTO; SOUZA, 2010, p.55).

Deste modo, percebe-se como é importante o papel do professor, ao propor estratégias, procedimentos e atividades que facilitem e proporcionem a compreensão em 
leitura dos alunos. Com isso, o professor torna-se um guia neste processo, porque exerce o papel de mediador na construção do conhecimento.

Para Masetto (2000), a mediação pedagógica do professor, refere-se à atitude, posicionamento e comportamento deste professor, tornando-se assim, um facilitador, incentivador e motivador do processo de aprendizagem da leitura. Nesta perspectiva, as estratégias de leitura se constituem em aliadas eficientes no processo de ensino/aprendizagem, pois elas desenvolvem habilidades leitoras de compreensão e interpretação, as quais contribuem para a formação do leitor independente, crítico e autônomo.

Para Solé (1998), as estratégias têm como características próprias não detalharem nem prescreverem totalmente o curso da ação. As estratégias se constituem em um procedimento de caráter elevado que envolve a formulação de objetivos a serem realizados, planejamento de ações desencadeadas com a finalidade de atingi-los, a avaliação e a possível mudança. Não devem ser tratadas como técnicas precisas, infalíveis ou habilidades específicas, pois o uso das estratégias se caracteriza pela capacidade de representar, analisar os problemas e a flexibilidade para buscar soluções.

Girotto e Souza (2010) e Solé (1998), defendem o emprego das estratégias de leitura em todas as etapas no ensino de leitura, que seria o antes, o durante e o depois. Para Solé (1998), o professor, no processo do "antes da leitura", deve oferecer aos alunos finalidades/objetivos para a leitura, levando os alunos a ativarem os conhecimentos prévios, incentivando suas previsões e perguntas. Já no processo do durante a leitura, deve-se avaliar a consistência do texto e sua compatibilidade com o conhecimento prévio. E, no processo "depois da leitura", espera-se que o leitor seja capaz de fazer resumos, destacando as ideias principais e identificando os elementos implícitos no texto.

Outro aspecto destacado por Girotto e Souza (2010) é que a compreensão do texto depende da fluência de cada aluno, ou seja, o aluno precisa receber instruções. E cabe ao professor, enquanto mediador, planejar e propor atividades cada vez mais complexas que irão possibilitar ao leitor autoconfiança e assim ser capaz de ler com maior segurança.

Como ressalta Solé (1998) é fundamental que os professores reflitam sobre o trabalho com a leitura na complexidade desse processo e sobre a capacidade que as crianças têm de enfrentarem essa complexidade. Cabe aos professores oferecerem ajuda para os alunos superarem os desafios da atividade de leitura. 
Percebe-se assim, que se podem realizar diferentes atividades com a leitura, buscando sempre oferecer uma leitura significativa para a criança, para que esta compartilhe e compreenda as finalidades da leitura. Para isso, a criança deve ter conhecimento sobre quais os objetivos pretendidos com aquela leitura e saber que pode contar com a presença do professor, que irá auxiliá-la nesse processo.

No que se refere às atividades voltadas para o ensino de leitura, estudos têm mostrado que estas ainda se encontram centradas na decodificação, ou seja, em atividades mecânicas e, muitas vezes, desvinculadas dos usos socais da língua. Deste modo, não são trabalhadas as funções sociais que a língua expressa, não despertando o interesse dos alunos e não contribuindo para desenvolver a aquisição de habilidades para uma dimensão de interação verbal configurando-se como, “[...] uma atividade incapaz de suscitar no aluno a compreensão das múltiplas funções sociais da leitura (muitas vezes, o que se lê na escola não coincide com o que se precisa ler fora dela)". (ANTUNES, 2003, p.28).

A atividade de leitura é uma atividade de interação entre os sujeitos, tanto entre o autor, quanto o leitor, o qual busca recuperar, interpretar, compreender o que foi escrito pelo autor, no exercício de atribuir sentido ao texto lido. No entanto, para que esta relação de interação aconteça, não basta apenas que exista o texto escrito pelo autor, vários fatores influenciam a interação e compreensão do leitor em relação ao texto, pois muito do que conseguimos compreender durante a leitura faz parte do conhecimento prévio que trazemos.

Como ressalta Antunes (2003), “[...] a leitura é parte da interação verbal escrita, enquanto implica a participação cooperativa do leitor na interpretação e na reconstrução do sentido e das intenções pretendidas pelo autor.” (ANTUNES, 2003, p.66). Dessa forma, a atividade de ler é um complemento da atividade de produção escrita, sendo também uma atividade de interação entre os sujeitos. Isto ocorre porque a leitura proporciona o acesso aos aspectos da escrita, além dos conhecimentos que já foram produzidos historicamente, e do prazer estético, que o ato de ler oportuniza.

Assim, compreendemos que a atividade de ler propicia ao leitor acesso a novas ideias, conceitos, informações, sobre o mundo, os acontecimentos e as pessoas. E, também, possibilita a experiência de ler pelo prazer estético, pelo fato de gostar de ler, "para admirar, para deleitar-se com as ideias, com as imagens criadas, com o jeito bonito de dizer literalmente as coisas. Sem cobrança, sem a preocupação de qualquer prestação de contas posterior”. (ANTUNES, 2003, p.71). 
Pela leitura conseguimos adquirir e apreender os padrões gramaticais (morfológicos e sintáticos), formas de organização sequencial, vocabulário especifico dos diversos gêneros textuais. Nesse sentido, a leitura exerce uma função tríplice, na qual, o leitor pode realizar uma leitura para informar-se sobre determinado assunto, adquirindo novos conhecimentos de mundo; ler por prazer, para deleitar-se e, por último, ler para compreender as características da escrita.

Para Antunes (2003, p.77),

Pode-se prever a existência de uma leitura não uniforme, diferente, portanto, em cada circunstância, dependendo do tema, do nível de formalidade e do gênero do texto lido ou, ainda, dos objetivos e dos motivos implicados no ato de ler. Assim, conforme variem os gêneros de texto (editoriais, artigos, ensaios, notícias, anúncios, avisos, relatórios, instruções de uso, editais, contos, poemas), conforme variem os objetivos pretendidos para a leitura (leitura informativa, leitura recreativa, leitura instrumental etc.), variam também as estratégias a serem utilizadas. O grau de familiaridade do leitor com o conteúdo veiculado pelo texto interfere, também, no modo de realizar a leitura. Ou seja, ninguém lê da mesma maneira, sempre, não importa que material. Até mesmo um jornal traz seções diferentes que suscitam diferentes comportamentos de leitura.

Nesse sentido, o ato de ler envolve diversos processos e estratégias, não dependendo apenas do contexto linguístico, mas também do contexto extralinguístico do texto. Ou seja, o sentido do texto se encontra tanto no texto como no leitor, e não apenas em um, isoladamente. Por isso que, neste estudo, concebemos a concepção interacional da língua, na qual a compreensão de sentido do texto dá-se através da interação entre autor-texto-leitor.

Para Koch e Elias (2006, p.10):

[...] na concepção interacional (dialógica) da língua, os sujeitos são vistos como atores/construtores sociais, sujeitos ativos que dialogicamente se constroem e são construídos no texto, considerando o próprio lugar da interação e da constituição dos interlocutores.

Neste contexto, o papel do professor como mediador e o uso de estratégias no ensino de leitura têm sido destacados como fundamentais para formar alunos que compreendem o que leem. Ancorado em tais questões o presente artigo discute dados de pesquisa realizada em uma cidade do interior do sudeste goiano, realizada com o objetivo de perceber como tem se desenvolvido o trabalho com a leitura no $3^{\circ}$ ano do 
Ensino Fundamental I e quais estratégias de leitura são utilizadas no trabalho desenvolvido na sala de aula. $\mathrm{O}$ foco no terceiro ano se justifica por compreendermos que este é o período em que está se consolidando o processo de alfabetização, quando deveriam estar sendo reforçadas estratégias de leitura voltadas para levar os alunos a construir os sentidos do texto, fazendo inferências, visualizações e relações entre textos.

A pesquisa foi realizada a partir de uma abordagem qualitativa de caráter etnográfico. Como instrumento de coleta de dados foi realizada uma entrevista semiestruturada e observadas cinco aulas. No âmbito da presente discussão, problematizamos os dados coletados durante cinco observações realizadas na sala de uma professora do terceiro ano da primeira fase do Ensino Fundamental.

O primeiro dado salientado nas observações foi a preocupação da professora em trabalhar com diferentes gêneros textuais como notícia, charge, propaganda, outdoor, narração: seleção de argumento, narração: interpretação de foto, anúncio, história em quadrinhos e bilhete. Tal fato foi observado já na primeira aula assistida quando inicialmente, a professora dividiu os alunos em duplas e distribuiu uma atividade xerocopiada com um gênero textual diferente para cada dupla. Distribuiu, também, revistas para as duplas em que a atividade proposta solicitava o recorte de uma notícia, uma charge ou uma propaganda de outdoor. Os alunos deveriam fazer inicialmente uma leitura silenciosa.

Durante a atividade a professora se deslocou pela sala, passando pela carteira dos alunos perguntando se eles estavam tendo alguma dúvida em relação à atividade. Foi possível perceber que muitos alunos tinham dificuldade em realizar a leitura e interpretar o que estava sendo cobrado nas atividades. Nestes casos, a professora realizou a releitura do enunciado para as duplas com dificuldades. Após a professora realizar essa leitura eles conseguiam responder à atividade proposta. Ao passar alguns minutos, ciente de que todos haviam terminado a tarefa, ela solicitou que cada dupla se dirigisse ao quadro para ler e explicar sobre o exercício realizado. A primeira dupla apresentou uma notícia retirada de uma revista, eles começaram a ler a notícia. Quando eles terminaram a professora indagou: "Professora: Do que está falando esta notícia que vocês leram? Alunos: Sobre os animais. Professora: $\underline{\text { Sobre quais animais estava }}$ falando nessa notícia?".

A partir da fala da professora percebemos que ela realizou um processo de mediação ao questionar os alunos sobre a notícia que estavam apresentando, percebe-se que o objetivo era fazer com que os alunos reconhecessem qual o assunto do texto. A 
partir das questões propostas, o que inferimos é que a professora provocou os alunos para que prestassem atenção a determinados aspectos do texto, como por exemplo, sobre quais animais a notícia estava tratando, o que contribuiu para ativar o conhecimento prévio destes (SOLÉ, 1998).

Nesse momento vários alunos começaram a comentar sobre os animais que gostavam e dos quais eles conheciam: "Aluno 1 - Na minha casa tem um gato. Aluno 2 - Na minha um cachorro e um papagaio. Aluno 3 - La na fazenda tem vaca, porco, cachorro, periquito. Aluna 4 - Um dia tia meu pai matou uma cobra La em casa".

Percebemos que a professora fez com que os alunos ativassem o conhecimento prévio, a partir do momento que relataram sobre a experiência e vivência que eles possuíam com os animais. Durante a apresentação da primeira dupla, a professora levou os alunos a repensarem sobre a temática do texto lido, levando-os a inferirem novas ideias a partir da leitura da notícia sobre os animais. Entendemos que neste momento a professora trabalhou a estratégia da predição, quando procurou levá-los a inferir o conteúdo do texto a partir das experienciais e vivências que eles já possuíam sobre os animais. Nesse sentido, levar os alunos a fazerem inferências permitiu que eles relembrassem e recapitulassem o que já sabiam, além de colaborar para a construção de novos conhecimentos. As inferências resultaram de um diálogo com o texto, e permitiu a compreensão deste texto, pois ao inferirmos estamos compreendendo o que lemos (ANTUNES, 2003).

Dando seguimento à atividade a professora questionou:

Professora: Mas a gente pode matar os animais?

Aluno: não.

Aluno: a gente vai preso, né tia?

Professora: Nós não podemos maltratar os animais, alguém sabe qual o órgão público responsável por proteger os animais?

Aluno: meu pai falou que é o IBAMA tia

Professora: Muito bem, se o IBAMA pegar a gente matando algum animal, leva a gente preso, não é? Agora vamos para outra dupla senão, não vai dar tempo.

Neste caso observamos que a questão levantada é subjetiva, não precisando do texto para ser respondida, a resposta pode ficar a cargo do aluno. Marcuschi (2005), ao fazer uma reflexão sobre a tipologia de perguntas de compreensão encontradas nos livros didáticos, considera que as questões subjetivas pouco têm a ver com o texto lido e acabam não contribuindo para a formação do leitor crítico. Foi o que percebemos com 
esta atividade, quando as questões discutidas a partir do texto lido não retomam o conteúdo do texto.

Após encerrar a explicação sobre o IBAMA, a professora pediu que a dupla se sentasse e chamou a dupla seguinte à frente do quadro. A dupla apresentava uma história em quadrinhos da Turma da Mônica, a professora perguntou sobre o que estava falando e os alunos começaram a falar ao mesmo tempo: "Aluno 1: Que a Magali queria comer tudo. Aluno 2: ela ficava pedindo comida. Aluno 3: a mãe dela levou ela no médico. Alunos 4: é porque ela come muito".

Novamente percebemos que a professora tentava levar os alunos a reconhecerem qual o assunto da história em quadrinhos. Porém, após os alunos relatarem o assunto da história a professora não realizou intervenções ou outros questionamentos para a dupla. Ela apenas aguardou os alunos ficarem em silêncio, e chamou a próxima dupla à frente.

Os alunos leram as atividades referentes a uma propaganda de chiclete, realizando a leitura das perguntas e respostas. A professora não fez comentários sobre as atividades. As duplas seguintes só realizaram a leitura do que haviam respondido na atividade e sentaram-se. Não foram realizadas quaisquer intervenções ou perguntas para as duplas.

Foi possível perceber que os alunos acabaram por se alongar para realizarem as atividades, o que interferiu no momento da apresentação. Pelo fato da professora não ter muito tempo, acabou por não dar o retorno necessário sobre as atividades para todas as duplas durante a apresentação. Deste modo, a organização do tempo da aula interferiu no trabalho da professora que não reforçou e não levou os alunos à reformulação da atividade, configurando-se como uma ausência de mediação. Com isso, o aluno pode enfrentar dificuldades de desenvolver a metacognição no processo de leitura, pois, ao não receber, seja o reforço da atividade seja a necessidade de sua reformulação, sua capacidade de controlar informações já obtidas com a leitura do texto ou a necessidade de refutá-las ou ampliá-las, fica comprometida.

O que se percebeu nesta atividade é que a professora buscou trabalhar com a diversidade de gêneros textuais buscando atender às orientações atuais. A inserção dos gêneros no processo de ensino-aprendizagem tem sido destacada como necessária, uma vez que colabora para o desenvolvimento da linguagem e da competência metagenérica que para Koch e Elias, (2006, p.103) possibilita aos indivíduos “[...] interagir de forma conveniente, na medida em que se envolvem nas diversas práticas sociais". Tal competência propicia a compreensão e a produção dos diferentes gêneros. 
No entanto, o único momento que percebemos o uso de estratégias de leitura foi durante a apresentação da primeira dupla. No decorrer da aula, observamos que a professora não fez uso de estratégias de leitura que levassem os alunos a confirmar ou reformular as leituras realizadas.

Na segunda e a na terceira aula observadas, apesar de terem anunciado que iriam trabalhar a leitura de textos com os alunos, as professoras Ana e Bruna realizaram atividades voltadas para o ensino dos tempos verbais e da ortografia. No primeiro caso, a professora Ana trabalhou a leitura de uma manchete, colada em um cartaz na sala de aula, para que os alunos identificassem se os fatos relatados ocorriam no passado ou no presente. No segundo caso, a professora Bruna trabalhou atividades que tinham como objetivo levar os alunos a perceber a escrita de palavras que continham dígrafos formados com o h como: $\mathrm{CH}, \mathrm{LH}$ e $\mathrm{NH}$. As atividades foram realizadas a partir da leitura do poema de Pedro Bandeira: "Maluquices do H”, que foi lido em voz alta pela professora. Porém, não foram levantadas questões, fossem orais ou escritas, voltadas para a construção do sentido do mesmo. Nos dois casos o que ficou evidenciado foi a leitura do texto como pretexto para a realização do ensino de conteúdos gramaticais e ortográficos desvinculados de uma reflexão sobre tais conteúdos e dos usos que se faz da língua fora do contexto escolar. Neste caso, a atividade de leitura não teve como objetivo levar o aluno a perceber a dimensão da interação verbal, como salienta Antunes (2003, p.27) para quem “[...] nessas circunstâncias, não há leitura, porque não há encontro com ninguém do outro lado do texto".

Na quarta aula, da professora Bruna do $3^{\circ}$ ano, foi trabalhada uma atividade com 05 textos diferentes: 02 Histórias em Quadrinhos e 03 textos pequenos seguidos de questões de interpretação. Ela iniciou a aula pedindo aos alunos que formassem grupos de 03. Após a formação de todos os grupos, ela entregou uma atividade xerocopiada para cada aluno. Todos os alunos receberam a atividade com os 05 textos. A professora dividiu as atividades entre os grupos, cada grupo ficou responsável pela leitura de um texto diferente e de responder às questões de interpretação deste.

A professora pediu que os alunos realizassem a leitura em grupo e depois respondessem às questões. Após alguns minutos dados para que os alunos terminassem a atividade, foi realizada a correção. Ela informou que começaria com o grupo 01, e que somente o grupo iria responder às questões do texto 01 . Se os alunos do grupo 01 respondessem errado, ela iria fazer a pergunta para o restante da turma e então eles teriam a chance de responder. Ela se dirigiu ao grupo 01 e fez inicialmente questões 
voltadas para a compreensão da superfície do texto tais como: o título do texto lido e seu autor.

Em seguida, a professora leu a História em Quadrinho em voz alta e a questão que se seguia, era voltada para levar os alunos a inferirem sobre a história, ao perguntar o que a expressão "da hora" afirmada por Monica sobre o desenho do Cascão significava. A professora realizou a leitura da questão, mas os alunos não conseguiram responde-la. Ao final, a professora informou a alternativa correta.

Seguiu-se à leitura do texto lido pelo grupo 2 e as questões de interpretação que, inicialmente, indagavam o título e o autor do texto. Uma das questões do referido texto, tinha como objetivo levar os alunos a fazerem inferências. Foi o caso da questão 06, que afirmava sobre a mania de Talita de dar nome de gente aos objetos da casa, e questionava sobre o que demonstrava ser Talita, uma menina curiosa, exagerada, estudiosa ou criativa?

Esta atividade colaborou para que os alunos fizessem inferências, pois a resposta não estava explícita no texto, o que, de acordo com Girotto e Souza (2010), contribui de forma fundamental para a compreensão do texto pelo leitor, ou seja, ao inferir os leitores fazem uso de seus conhecimentos prévios e estabelecem uma relação com o texto, fazendo conexões, deduções, até chegarem a uma resposta.

$\mathrm{Na}$ atividade do texto 05 , a professora iniciou lendo o título do texto "Vida de Passarinho” e depois fez a leitura deste para os alunos. Em seguida ela lê a questão 20, que questiona sobre qual o intuito do autor da história em quadrinhos ao escrever essa história, que continha alguns versos do poema "Canção do exílio" de Gonçalves Dias.

Percebemos que esta questão está voltada para levar os alunos a inferirem, tendo que fazer conexões, entre o poema de Gonçalves Dias e a crítica implícita sobre o desmatamento. Podemos caracterizar essas conexões como de texto-mundo, ou seja, o leitor deve estabelecer uma relação com o texto e com algum acontecimento global.

Nesse sentido, conforme Marcuschi (2005) perguntas inferenciais exigem que o leitor tenha uma bagagem de conhecimentos prévios, conhecimentos textuais, contextuais e enciclopédicos, para que consiga realizar uma análise crítica, chegando a uma resposta.

Em uma das atividades propostas, os alunos responsáveis respondem a questão equivocadamente. Então, a professora pergunta para o restante da sala, mas todos respondem errado. Ela fala qual a resposta eles deveriam marcar e passa para a leitura da questão seguinte, sendo que desta vez, os alunos respondem satisfatoriamente. 
Nesta atividade, foi possível perceber que a principal estratégia de leitura utilizada para levar os alunos a perceber os sentidos dos textos lidos, foi reler para os alunos as questões em que eles tiveram dificuldades de entendimento. Nesta releitura não foi percebida outras intervenções que levassem os alunos à reelaboração de suas respostas. Foi o caso da questão relacionada à história da Mônica. Diante da dificuldade dos alunos em entender o sentido da expressão: "Da hora", a opção da professora foi fornecer a resposta correta, sem oferecer mais pistas que levassem os alunos a realizar a inferência necessária para entender o texto.

O que se pode perceber é que das três questões inferenciais presentes na atividade que estava sendo trabalhada, os alunos conseguiram responder apenas uma. Podemos deduzir que isso ocorreu porque questões inferenciais são complexas, por se tratarem de perguntas onde a resposta não está explicita no texto e sim, nas entrelinhas deste. Deste modo, por não ter havido uma mediação por parte do professor com os textos que estavam sendo trabalhados, os alunos não conseguiram compreender, não realizando nenhuma inferência e não chegando a uma resposta correta das questões. Deste modo, podemos afirmar como Girotto e Souza (2010, p.76) que "[...] se os leitores não inferem, então, não entendem a essência do texto que leem".

$\mathrm{Na}$ quinta aula observada da professora Bruna, do $3^{\circ}$ ano, ela trabalhou com o livro "O dono da bola" de Ruth Rocha e com questões de interpretação do texto. O texto foi exibido para os alunos através de data show. Ao final da exibição, as atividades de interpretação foram entregues em uma folha xerocopiada.

Concluída a leitura do livro, os alunos foram questionados se haviam entendido a história e se haviam gostado da mesma. Estas são perguntas que se caracterizam como questões subjetivas, que não proporcionam ao leitor um aprofundamento do texto, apenas o trabalham de maneira superficial. A resolução de tais questões não necessita que o aluno volte ao texto para respondê-las, pois qualquer resposta será válida. Marcuschi (2005, p.56), a respeito da solução de perguntas subjetivas, diz que "[...] trata-se de uma resposta que não assume posição alguma, não contribui para a formação do raciocínio crítico".

Dando seguimento à atividade, a professora entrega uma folha xerocopiada com um texto adaptado do livro "O dono da bola", de Ruth Rocha, seguido de questões de interpretação para os alunos. Na análise da atividade, o que pudemos ver é que ela foi composta em sua maioria de questões objetivas e subjetivas. Para Marcuschi (2005), as questões objetivas são perguntas que não têm como objetivo o processamento do texto 
lido, e o enfocam apenas de maneira superficial. Tais questões restringem-se à solicitação de informações já explícitas na superfície do texto. Esse tipo de pergunta volta-se apenas para a decodificação e cópia, não exigindo do leitor uma compreensão do texto lido. Quanto às de cunho subjetivo, estas dispensam a voz do ator e a compreensão do texto, buscando apenas a opinião do leitor a respeito do texto. Nestes casos, há uma ausência de trabalho voltado para levar o aluno a questionar o texto ou buscar informações que estão ausentes, configurando-se em uma atividade de leitura que se limita a recuperar os elementos literais e explícitos do texto, ocorrendo, como salienta Antunes (2003), uma atividade de leitura "puramente escolar".

\section{Considerações}

Durante as aulas a professora procurou trabalhar com textos de diferentes gêneros como poemas, livro literário e histórias em quadrinhos. Tal diversidade é importante porque, como ressalta Costa (2004), quando a criança entra em contato com diversos gêneros estará se apropriando de um conjunto de instrumentos que elevará seu nível de letramento.

Por outro lado, concluímos que durante as aulas a professora realizou uma prática híbrida quando ao mesmo tempo em que procura levar para a sala de aula textos de gêneros variados, e procura levar os alunos a ativarem os seus conhecimentos prévios, antes da leitura dos textos, se vale de questões de interpretação voltadas apenas para a superfície do texto ou para inculcar valores morais nos alunos, numa perspectiva claramente tradicional de ensino de leitura, conforme salientam Kleiman e Martins (2007, p.291): “[...] executando um trabalho de hibridização ou de bricolagem, em que mistura sua leitura particular das orientações que tomam a leitura como um processo de interação entre sujeitos com elementos próprios da pedagogia tradicional”.

Por fim, vale ressaltar que as estratégias de leitura contribuem para a formação do leitor potencializando meios para o amadurecimento e autonomia em relação à compreensão e interpretação do texto. Nesse sentido, a mediação pedagógica é fundamental na constituição da formação do leitor. O hibridismo, percebido na prática pedagógica, nos leva a observar que ainda são muitos os desafios a serem enfrentados para a formação do leitor crítico e reflexivo. 


\section{REFERÊNCIAS}

ANTUNES, I. Aula de português: encontro e interação. 1.ed. São Paulo: Parábola, 2003.

BAJARD, E. Caminhos da escrita: espaços de aprendizagem. São Paulo: Cortez, 2002.

BRASIL. Ministério da Educação. Secretaria de Educação Fundamental. Parâmetros Curriculares Nacionais: Língua Portuguesa. Brasília: MEC/SEF, 1997.

COSTA, S. R. Interação, alfabetização e letramento: uma proposta de/para alfabetizar, letrando. In: MELLO, M. C.; RIBEIRO, A. E. A. (Org.). Letramento: significados e tendências. Rio de Janeiro: Wak, 2004. p.13-49.

FISHER, S. R. História da leitura. São Paulo: Ed. da UNESP, 2006.

GIROTTO, C. G. G. S.; SOUZA, R. J. Estratégias de leitura: para ensinar alunos a compreender o que leem. In: MENIN, A. M. C. S. et al. (Org.). Ler e compreender: estratégias de leitura. Campinas: Mercado das letras, 2010. p.45-114.

KLEIMAN, A. B.; MARTINS, M. S. C. Formação de professores: a contribuição das instancias administrativas na conservação e na transformação de práticas docentes. In: KLEIMAN, A. B.; CAVALCANTI, M. C. (Org.) Linguística aplicada: suas faces e interfaces. Campinas: Mercado das Letras, 2007. p.273-298.

KOCH, I. V.; ELIAS, V. M. Ler e compreender: os sentidos do texto. São Paulo: Contexto, 2006.

MARCUSCHI, L. A. Produção textual, análise de gêneros e compreensão. São Paulo: Parábola Editoria, 2005.

MASETTO, M. T. Mediação pedagógica e o uso da tecnologia. In: MORAN, J. M.; MASETTO, M. T.; BEHRENS, M. A. Novas tecnologias e mediação pedagógica. São Paulo: Papirus, 2000. p.133-173.

MOURA, A. A. V.; MARTINS, L. R. A mediação da leitura: do projeto à sala de aula. In: BORTONI-RICARDO, S. M. et al. (Org.). Leitura e mediação pedagógica. São Paulo: Parábola, 2012. p.87-112.

ORLANDI. A leitura e os leitores. Campinas: Pontes, 1998

SOLÉ, I. Estratégias de leitura. 6.ed. Porto Alegre: Artmed, 1998.

\section{Como referenciar este artigo}

ROSSI, Maria Aparecida Lopes; PERES, Selma Martines; SILVA, Fernanda Siqueira da. Estratégias de leitura e mediação do professor: o desafio de formar leitores no 
terceiro do ensino fundamental. Revista Ibero-Americana de Estudos em Educação, Araraquara, v.11, n. esp. 4, p. 2414-2429, 2016. Disponível em: <http://dx.doi.org/10.21723/riaee.v11.n.esp4.8906>. E-ISSN: 1982-5587.

Submetido em: setembro/2016

Aprovado em: novembro/2016 